CASE 4. - J. W- European, age thirty, admitted under Dr. Benson's care on July 10th, 1880. Had been treated by gradual dilatation some time ago, but strictnre recurred, and urine passes now in a minute stream. Fistulous opening in perineum. No. 4 catheter a boule passed with difficulty. Catheter withdrawn afterwards, and there was so much difficulty in reintroducing it, that Mr. Teevan's instrument was used, and the stricture cut on the 13th. The strictured portion not having been completely divided, I used the urethrotome again on Aug. 1st, and after that there was no further difficulty. No. 12 English catheter passed freely, and the man was discharged on the 22nd, with a full-sized instrument given him to pass occasionally, the fistula having closed some time previously-viz., soon after the urethrotomy.

In the last case there was a little fever after the operation, but not more than followed catheterism previously, and it was readily controlled by quinine and opium. I also noticed that in No. 4 a well-curved catheter with a stilet in it, so as to direct its point along the roof of the urethra, passed more readily than a soft straight catheter or bougie aे boule, the explanation of which I assumed was, that the latter became engaged in the old fistulous orifice or annular portion of the stricture, whereas the former glided over or through the gap made by the knife, and which was ultimately filled up with the "cicatricial splice," which remained less prominent than the indurated part in the unincised portion.

Four cases are of course too few to draw any conclusions from, but if, according to the highest authorities, organic stricture is not curable, strictly speaking-i. e., the indurated structures giving rise to it are never completely removed, and the urethral canal restored to its original healthy state, and there is a liability to its recurrence, and if it is an "operation perfectly safe and easy to perform," then it would seem to me that internal urethrotomy is the operation for severe and obstinate cases, if not even for milder ones where, as in India, the surgeon may lack the necessary instruments occasionally, or the patients be unreasonable and disinclined to submit to lengthened treatment, and want to leave before the "gradual dilatation" process has more than half done its work. At all events I now feel myself, whether rightly or wrongly, that I can attack most cases of stricture and treat them efficiently by internal urethrotomy, without having the prospect of having to puncture the bladder before my eyes as previously whenever I failed with catheterism; that is, of course, wherever the filiform bougie of Mr. Teevan's instrument will pass, and the percentage of cases where it ought to fail is, I think, very small.

\section{THE CHLOROFORM DEATH-BILL FOR TWELVE MONTHS. ${ }^{1}$}

BY ERNEST H. JACOB, M.D.,

PHYSICIAN TO THE LEEDS DISPENSARY AND THE LEEDS FEVER HOSPITAL.

Is a previous communication ${ }^{2}$ I reviewed the great change that had occurred during the past few years in the substitution of ether for chloroform in surgical practice. In 1876 a return from the anæsthetists of the London and other large hospitals revealed the fact that, save for the aged and infants, ether had taken the place of chloroform in nearly all our great surgical centres, and not only this, but that the change was felt by the officers in charge of the administration to be one greatly to the advantage of the patients as regards their subsequent condition, as well as the mere aroidance of death while under the influence of the drug.

And yet, during the past twelve months, no less than twenty-tive deaths have occurred from chloroform-I ought rather to say, have been recorded, for, no doubt, many occur which it is convenient and possible to say nothing about. Of these twenty-five, seventeen only occurred in Great Britain, fifteen being in hospital, and eight in private practice. The operations were mostly of the simplest kind. Dressing wounded fingers or toes, three; necrosis, four; extraction of teeth, two; amputation of the breast and lithotrity, one

1 Read before the Leeds and West Riding Medico-Chirurgical Society.

2 On Ether as an Anæsthetic, THE LANCET, vol, ii. 1879, p. 539. each ; and one for applying a splint to a child's leg. The deaths appear to have occurred in the usual way from sudden syncope. As regards the post-mortem appearances, which are noted in fourteen cases, in five all organs were perfectly healthy. In eight only the heart was more or less "fatty" or "flabby," and in one there was emphysema of the lungs.

As regards locality, two deaths took place in the Edinburgh Infirmary, where, I believe, ether is not in use; two in the London Hospital, where ether is extensively used; and three in Liverpool.

During this period five deaths from other anæsthetics have been recorded. One each from ethydene dichloride and ethyl dibromide, and three from ether. Of the latter two occurred in America, one during extraction of teeth, no particulars being given, and one during an operation for hip disease, the patient suffering from valvular disease of the heart. The remaining case, the only one in England, was that recently reported by Mr. Hartley, which conld not be said to be due to the anæsthetic, as the patient was almost in articulo from intestinal obstruction when the operation was commenced.

It can hardly be too strongly urged that the fatality of an anæsthetic cannot be deduced from the experience of one observer. The cases must amount to tens of thousands. During the past few years, however, there has been no lack of material for statistical inquiry, and the result is to be read in the facts I have stated.

A death from an anæsthetic administered for a trivial operation cannot be regarded as anything but a serious calamity. It is not for me to say that a grave irresponsibility rests on the surgeon who employs chloroform when a safer anæsthetic is available, but I think it cannot be long before the voice of the profession (if not of the public, as in America) demands some explanation for the use of an agent whose victims are numbered by hundreds.

Leeds.

\section{IN TR O D UCTORY ADDRESS,}

Delivered at the Opening of the Winter Session of the School of Medicine, Surgeons' Hall, Edinburgh.

BY DR. FRANCIS W. MOINET.

GENTLEMEN,-It has devolved upon me in the name of your teachers to address to you this morning a few words of welcome and encouragement on the occasion of the commencement of the medical session. We welcome you as fellow students in a noble profession, which has for its aim the prevention and relief of human suffering, in striving to accomplish which you will find ample reward for all the labours of mind and body you may expend upon it. I take it for granted, gentlemen, you have chosen your profession thoughtfully for the love of it, because unless you feel your hearts are in the work you will neither do justice to yourselves nor to your work. It is one which should thoroughly commend itself to you in its aim and endeavours apart from all extrinsic questions as mere pecuniary reward. Now is the time to think of your work only, and how best you are to prepare yourselves for its responsible duties. In thinking over what I would address you upon this morning, it appeared to me that our time would be most profitably occupied in directing your attention briefly to what $\mathbf{I}$ consider is the right spirit in which you should prosecute your studies. This I feel can best be done by trying to impress upon you the importance of entertaining a high opinion of your profession and a clear idea of its responsibilities; the first will make you careful to do nothing to tarnish its reputation, and the second should stimulate you in your work, so that you will do credit to yourselves and to the profession for which you are now going to prepare yourselves, and so maintain if not raise the estimation in which it is held by the public, and increase its power of usefulness. In treating your patients you should be satisfied that you have used all the possible means which science and experience have gathered for our use. This is the responsibility which you undertake when you go out into the world to practise your profession, and which, if properly realised by you now, will be the best stimulus to you to worls hard as students, by 